\title{
Yoga in Arterial Stiffness: A Review
}

\author{
Gaurav Kapoor, M.P.T. ${ }^{1}$, Sandeep Singh, Ph.D. ${ }^{2}$, Priya Chauhan, M.P.T. ${ }^{3}$, Aksh Chahal, Ph.D. ${ }^{4}$, \\ Anchit Gugnani, Ph.D. ${ }^{1}$
}

'Department of Physiotherapy, Jayoti Vidyapeeth Women's University, Rajasthan, India.

${ }^{2}$ Department of Physiotherapy, Faculty of Medicine, Punjabi University, Punjab, India.

${ }^{3}$ Department of Physiotherapy, UIAHS, Chandigarh University, Punjab, India.

${ }^{4}$ Maharishi Markandeshwar Institute of Physiotherapy and Rehabilitation, Maharishi Markandeshwar University, Haryana, India.

Received 20 September 2021 • Revised 16 December 2021 • Accepted 28 December 2021 • Published online 18 February 2022

\begin{abstract}
:
Non-communicable diseases; especially cardiovascular disease (CVD), is expected to be a leading cause of death worldwide through till 2030. Controlling this disease and its complications requires early recognition and surveillance, and as a result the accompanying health-care expenses can be kept under control. Looking back over the past, since 5 to 6 decades, studies have revealed an increase in CVD in India; ranging from $1.0 \%$ to $9.0 \%$ and $1.0 \%$ to $4.0-6.0 \%$ in both urban and rural areas, respectively. Arterial stiffness is defined as a decrease in an artery's ability to expand and contract in response to changes in pressure. Pulse Wave Velocity (PWV), which is the speed at which forward pressure is conveyed from the aorta via the vascular tree, is one of the simplest and oldest methods for determining it. Yoga, a mind-body practice that dates back to 5,000 Before Christ in India. It is regarded as a Vedic, ancient science, as a means of mental, bodily, and social existence, and has been increasingly used as a remedial measure. An comprehensive search of the electronic databases in PubMed/Medline, Web of Science, Scopus, Science Direct, Google Scholar, and Semantic Scholar for relevant publications was conducted using the keywords "Yoga and Arterial Stiffness." This current review, based on the scientific evidence, suggests yoga to pose and deliver health favourable benefits on PWV; particularly in adolescents as opposed to middle and geriatric populations. In addition, yoga is useful for young people with obesity, hypertension, and for those who lead a sedentary lifestyle. Yoga's beneficial effects on cardiovascular disease are related to a reduction in sympathetic activity as well as concomitant mental and physical relaxation.
\end{abstract}

Keywords: arterial stiffness, cardio vascular disease, physical activity, yoga

Contact: Assoc. Prof. Anchit Gugnani, Ph.D.

Department of Physiotherapy, Jayoti Vidyapeeth Women's University, Rajasthan, India.

E-mail: anchitgugnani19@gmail.com

() 2022 JHSMR. Hosting by Prince of Songkla University. All rights reserved.

This is an open access article under the CC BY-NC-ND license

(http://www.jhsmr.org/index.php/jhsmr/about/editorialPolicies\#openAccessPolicy).
J Health Sci Med Res 2022;40(5):599-606 doi: $10.31584 /$ jhsmr.2022863 www.jhsmr.org 


\section{Introduction}

Cardiovascular disease (CVD) is the leading cause of mortality around the globe. The progression of cardiovascular disease has been linked to arterial stiffness in the central arteries. ${ }^{1}$ Early detection and monitoring are vital to control this disease and its comorbidities in additional to controlling the associated health costs. Advancements in controlling the prognosis of CVD has already progressed in developed parts of the world. In India, in the past 50 to 60 years, many studies have documented an escalation in CVD; extending from $1.0 \%$ to $9.0-10.0 \%$ and $<1$ to $4.0-$ $6.0 \%$ in urban and rural locations. ${ }^{2}$ Furthermore, $63.0 \%$ of deaths were reported from non-communicable diseases, of which $27.0 \%$ were from CVD. ${ }^{3}$ Recent researches have shown the relationship between arterial stiffness and CVD. With an advancement in age, and associated cardiovascular risks; including, hypertension, diabetes mellitus, hypercholesterolemia, and end-stage renal failure, there occurs an increase in the chances of arterial stiffness; as per the surrogate measures of arterial stiffness. ${ }^{4}$ An alteration in arterial stiffness can be predicted before the clinical appearance of vascular signs and symptoms. Additionally, it can help to predict atherosclerosis, or can be a marker of atherosclerotic disease. Thereby, this works as a precursor of risk assessment as ones age progresses. ${ }^{5}$ Arterial Stiffness (AS) is best explained as a reduction in the capability of an artery to expand and contract with a change in pressure. ${ }^{6}$

AS is measured using one of the oldest and easy techniques: Pulse Wave Velocity (PWV), which is the speed at which the forward pressure is transmitted from the aorta through the vascular tree. ${ }^{7}$ It is a potential risk indicator of CVD, and has gained remarkable clinical and research importance.
Yoga is a mind-body practice that originated in India around 5,000 BC, and is recognized as a Vedic ancient science as a way of mental, physical, social life, which as been increasingly applied as a therapeutic intervention. ${ }^{8}$ The eight elements of Yoga asanas are: moral observances (Yama), self-disciplines (Niyamas), specific posture (asana), regulated breathing (Pranayama), Sensory withdrawal (Pratyahara), Concentration (Dharana), Meditation (Dhyana), and self-realization (Samadhi). ${ }^{9}$

Currently, limited data is available about the effect of different forms of Yoga on AS, with the first research being concluded in 2008, by CM Duren.

\section{Material and Methods}

An extensive search in PubMed/Medline, Web of Science, Scopus, Science Direct, Google Scholar and Semantic Scholar electronic database to review relevant articles, using the keywords "Yoga and Arterial Stiffness" was conducted. From this, a total of 1,079 articles were published from 1965 to June 1, 2021 (Figure 1). Ten articles found to fit into the inclusion and exclusion criteria. The inclusion criteria: included; clinical trials, controlled trials, randomized controlled trials that dealt with Yoga alone, or were in combination with any physical activity. Exclusion criteria: consisted of; research protocols, comments, articles having either abstract or conference proceedings, articles with lack or repetition of the same type of information.

\section{Yoga and its effect on arterial stiffness (Figure 2)}

Duren et al, in 2008, documented physical activity as having a great impact on arterial stiffness among the middle-aged population. Furthermore, the study concluded that yoga participants as having remarkably reduced arterial stiffness when compared to the sedentary lifestyle group. However, no difference was noted among the aerobic and yoga group. 


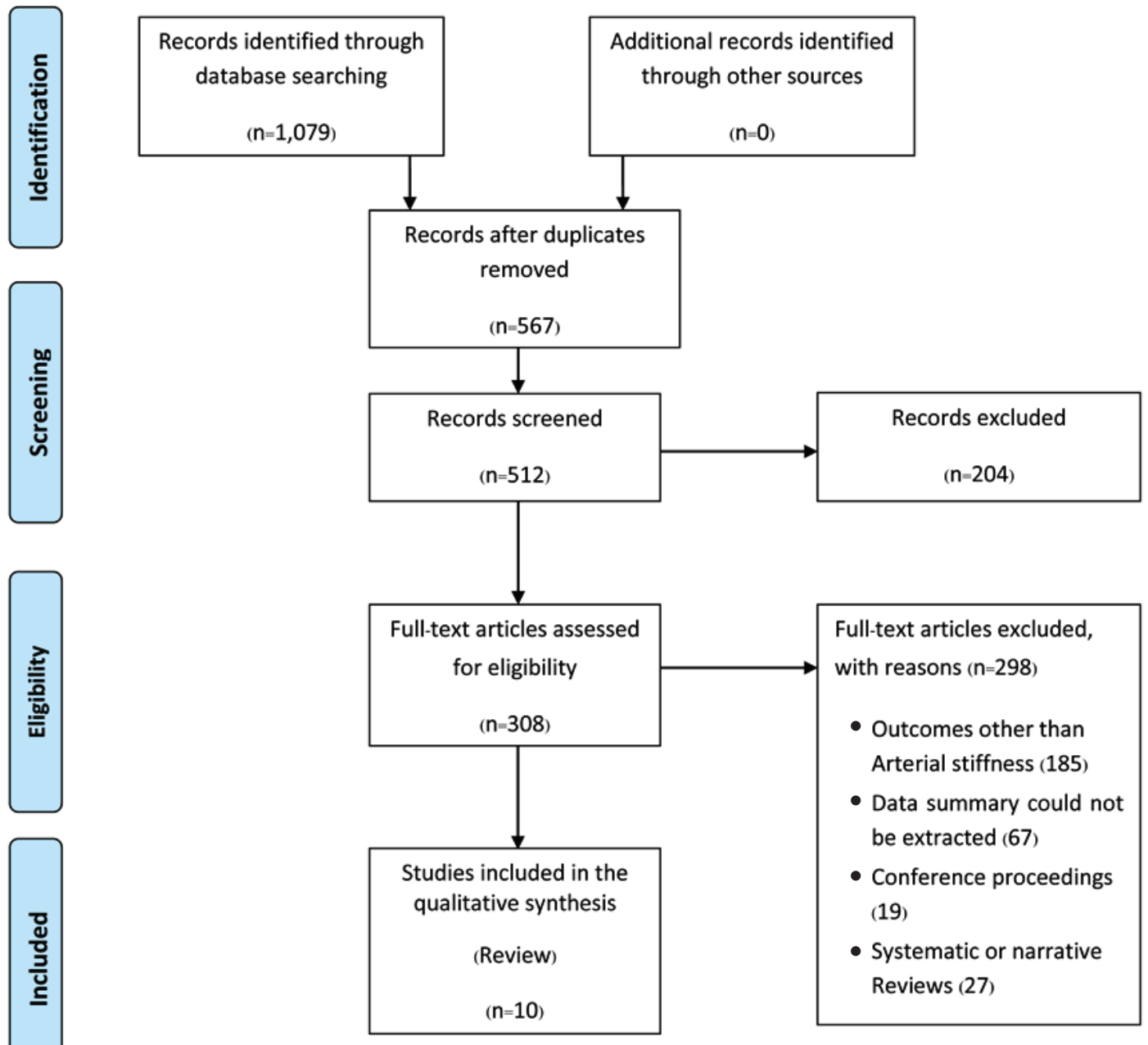

Figure 1 Prisma flow diagram on literature review

Hunter et al, 2013, demonstrated improvement in arterial stiffness with Bikram Yoga in the younger population (mean age \pm standard deviation, $30 \pm 1$ years), not in the older population (mean age \pm standard deviation, $53 \pm 2$ years), after 8 weeks of Bikram Yoga intervention. However, there was a significant decline in the insulin resistance index within the older group. ${ }^{10}$ Similarly, in 2016, the same authors documented a decline in brachial-ankle PWV among overweight/obese subjects, while no significant changes were noted in normal body mass index subjects.
However, emotional well-being and quality of life measures improved in both groups following 8 weeks of Bikram Yoga intervention. ${ }^{11}$ This is further supported by the study of Kumar et al, 2017, who concluded a remarkable decline in arterial stiffness in the young age obese population in comparison to the older population with obesity and nonobese adults, following a one-week integrated approach of yoga therapy in all three groups. ${ }^{12}$ In addition, Patil et al, 2015, concluded in a 12 weeks randomized control study that yoga is effective in reducing arterial stiffness with blood 
pressure, more so than brisk walking in elderly subjects with enhanced pulse pressure. Furthermore, yoga helps to improve endothelial function, with enhancement in the nitrous oxide bioavailability and a decline in sympathetic activity. ${ }^{13}$ Finally, Wooten et al, 2020, documented the improvement in cardiovascular ankle index, and noninvasive index of arterial stiffness in both groups (inflated and deflated blood flow restriction band) at a similar pattern among 20 healthy, young individuals. ${ }^{14}$

On the flip side, Kim in 2012, demonstrated no significant alteration in the arterial compliance and cardiovascular variables in the small and larger arteries, following 32 weeks of supervised yoga intervention in healthy premenopausal women. ${ }^{15}$ Similarly, Hunter et al, 2013; in a cross-sectional study, documented no difference in carotid arterial compliance and vascular functions among Hatha Yoga practitioners, and sedentary adults matched for age, body mass index, and aerobic activity level of fitness. Additionally, the same study documented no change in carotid artery compliance and $\beta$-stiffness in the interventional group. However, in both cross-sectional and interventional designs there occurred a reduction in $\mathrm{HbA} 1 \mathrm{c}$, after 12 weeks of intervention. ${ }^{16}$

In addition, Hunter et al, in 2018, found no change in brachial-ankle PWV among the middle aged sedentary population (40-60 years), following 12 weeks of intervention in the Hot, Thermoneutral Yoga and control group population. ${ }^{17}$ Finally, Pina et al, 2021, concluded that a single bout of Vinyasa Yoga helps in a reduction in the augmented index (Alx), with no change in the PVW among 30 people with a mean age group of 32 years and a history of yoga practice. Furthermore, this study documented the improvement in mood and lipid concentration. ${ }^{18}$

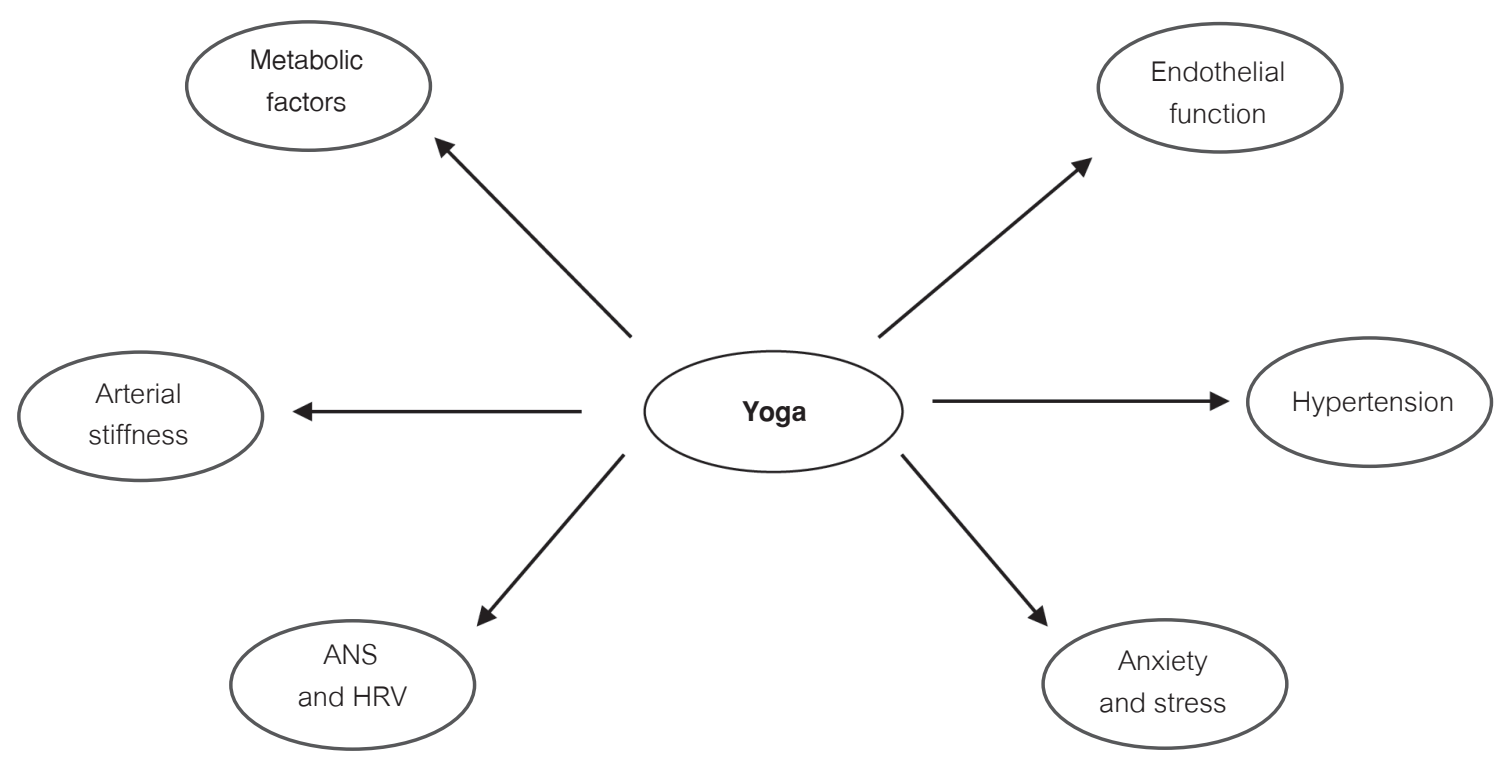

ANS=autonomic nervous system, HRV=heart rate variability

Figure 2 Effects of yoga on precursors of cardiovascular disease 
Yoga on autonomic nervous system (ANS) and heart rate variability (HRV) (Figure 2)

A study by Bhaskar et al, documented that long Sudarshan Kriya Yoga has a beneficial effect on cardiac autonomic tone, improvement in parasympathetic activity, and a reduction in sympathetic activity; thereby, creating balance in sympathovagal tone and psychophysiological relaxation. It may act as an aid to improve heart rate variability; a marker of cardiovascular health. ${ }^{19}$ Moreover, Trivedi et al, in a comparative study among women, documented the improvement in mood and heart rate variability within the Parasympathetic nervous system. ${ }^{20}$ This is in support of our review findings of a decrease in sympathetic activity in conjuction with psychological relaxation of the mind and body.

\section{Yoga in hypertension (Figure 2)}

Murugesan et al, concluded in their study that yoga is more effective in controlling systolic blood pressure, pulse rate and body weight in hypertensive subjects. ${ }^{21}$ It is in direct support of our review findings; in that yoga is more effective in controlling arterial stiffness in hypertensive and obese young adults.

In addition to this, the effects of yoga on blood pressure have been linked to a variety of mechanisms; including, age-related progression. However, supporting data suggests a strong link between oxidative stress and blood pressure. ${ }^{22}$ By influencing cell development and inflammatory responses through reduction-oxidationdependent signalling pathways, reactive oxygen species affect cardiovascular structures and functions. ${ }^{23}$ Increased vascular oxidative stress damages the endothelium, reduces nitric oxide production; by inhibiting EndothelialNitric Oxide Synthase (e-NOS) pathways, and impairs endothelium-dependent vasodilation. This results in an increased vascular tone, causing hypertension; thereby, increasing arterial stiffness. ${ }^{24}$ Furthermore, oxidative stress produces vascular media thickening, by stimulating smooth muscle cell proliferation and hypertrophy as well as collagen deposition, resulting in vascular lumen constriction. ${ }^{25}$ These findings suggest that oxidative stress may play a key role in hypertension development.

\section{Yoga in anxiety, and stress (Figure 2)}

$\mathrm{Li}$ et $\mathrm{al}$, in their review documented the reduction of stress and anxiety via yoga. ${ }^{26}$ Additionally, Azeez et al, in their findings of a randomized controlled trial, the short-duration breathing patterns of yoga, reduces the anxiety level in pre and post-operative cardiac surgery. ${ }^{27}$ Furthermore, Parswani et al, concluded that a mind-based stress reduction program is beneficial in lowering anxiety, depression, perceived stress, body mass index, and blood pressure in coronary heart disease subjects. ${ }^{28}$ This supports our review findings of the mood-boosting effect of yoga. There is an underlying notion that yoga has the ability to positively affect the biochemical and neurophysiological systems, by regulating the autonomic nervous system and stress response; thus, decreasing stress, anxiety and depression levels. ${ }^{29}$ Yoga inhibits the posterior or sympathetic part of the hypothalamus and restores autonomic regulatory reflex processes linked with stress, resulting in lower production of Adrenocorticotropic Hormones from the anterior pituitary gland. ${ }^{30}$ Yoga has become a popular stress-reduction technique for people suffering from anxiety, depression, and other mood disorders.

\section{Yoga on endothelial functions and metabolic} factors (Figure 2)

A study by Esfahani HN et al, supports our findings of endothelial functional improvement; a precursor of arterial stiffness, by their results in that yoga helps to improve the endothelial functions in subjects with migraine headaches. ${ }^{31}$ Yang, in her review documented the reduction in body weight, blood pressure, glucose level, and high cholesterol 
following yoga intervention. ${ }^{32}$ This is in support of our review findings in controlling metabolic factors; such as, blood glucose levels and, lipid profiles in young people practicing yoga.

Yoga's primary and secondary benefits in CVDs have been demonstrated in research; including people of all ages. In today's environment, stress has been discovered to be a major contributory factor in many diseases, including CVD; particularly among the younger population. ${ }^{33}$ In multiple studies, yoga has been found to lower CVD risk factors; such as, body weight, lipid profile, blood pressure, smoking, psychosocial stress, and type 2 diabetes mellitus. ${ }^{34-36}$ It is worth mentioning that yoga's secondary effects for CVD have only been documented in a few studies.
After coronary bypass surgery, yoga-based cardiac rehabilitation on Left Ventricular Ejection Fraction (LVEF), lipid profile, and psychological stress clearly reveals that yoga improves LVEF, lipids, hyperglycemia, stress, anxiety, and depression, and is shown to be an effective lifestyle intervention. ${ }^{37}$

On the flip side, no study has documented the direct and positive impact on arterial stiffness. Moreover, studies currently available are subject to the limitation of having a small group from the population. Further, studies with larger population sizes, and conducted over a longer duration are needed to formulate the reliable benefits of yoga on arterial stiffness.

Table 1 Benefits of yoga on cardiovascular disease

\begin{tabular}{|c|c|c|c|c|}
\hline \multicolumn{5}{|c|}{ Yoga } \\
\hline$\left[\begin{array}{l}\text { Arterial Stiffness in } \\
\text {-Middle aged } \\
\text {-Younger } \\
\text { Older }\end{array}\right.$ & $\begin{array}{l}\text { Autonomic Nervous } \\
\text { System and Heart Rate } \\
\text { Variability with } \\
\text { - Parasympathetic } \\
\text { activity } \\
\text {-Sympathetic } \\
\text { activity, } \\
\text {-Sympathovagal } \\
\text { tone and } \\
\text {-Psychophysiological } \\
\text {-Mood } \\
\text { HRV }\end{array}$ & $\begin{array}{l}\text { Hypertension in } \\
\qquad \begin{array}{l}\text {-Obesity } \\
\text { - Vascular oxidative } \\
\text { - stress } \\
\text { e-NOS }\end{array}\end{array}$ & $\begin{array}{l}\left.\right|_{\text {Disease }} ^{\text {Anxiety in }} \\
\text { - Coronary artery } \\
\text { Cardiac } \\
\text { surgery }\end{array}$ & $\begin{array}{l}\text { Endothelial } \\
\text { functions and } \\
\text { Metabolic factors } \\
\text { for } \\
\text { in CVD } \\
\text { becondary } \\
\text { benefits in CVDs }\end{array}$ \\
\hline
\end{tabular}

$\mathrm{HRV}=$ heart rate variability, e-NOS=endothelial nitric oxide synthase, $C V D=$ cardiovascular disease 


\section{Conclusion}

Gleaned from the scientific literature, the present review (Table 1) concludes yoga as having beneficial effects on pulse wave velocity; especially, in the young age group as compared to middle aged and elderly people. Furthermore, yoga proves to be more beneficial for young obese, hypertensive, and the sedentary lifestyle generation. The beneficial effects of yoga on cardiovascular disease are due to the decrease in sympathetic activity and psychological relaxation of both the mind and body.

\section{Conflict of interest}

There is no conflict of interest among the authors.

\section{References}

1. Duren CM, Cress ME, McCully KK. The influence of physical activity and yoga on central arterial stiffness. Dyn Med 2008; $7: 2$.

2. Gupta R, Mohan I, Narula J. Trends in coronary heart disease epidemiology in India. Ann Glob Health 2016;82:307-15.

3. World Health Organization. Cardiovascular disease in India [homepage on the Internet]. Geneva: WHO; 2018. Available from: https://www.who.int/india/health-topics/cardiovasculardiseases

4. Benetos A, Waeber B, Izzo J, Mitchell G, Resnick L, Asmar R, et al. Influence of age, risk factors, and cardiovascular and renal disease on arterial stiffness: clinical applications. Am J Hypertens 2002;15:1101-8.

5. Bonarjee VVS. Arterial stiffness: a prognostic marker in coronary heart disease. Available methods and clinical application. Front Cardiovasc Med 2018;5:64.

6. Cecelja M, Chowienczyk P. Role of arterial stiffness in cardiovascular disease. JRSM Cardiovasc Dis 2012;1:012016.

7. Shirwany NA, Zou MH. Arterial stiffness: a brief review. Acta Pharmacol Sin 2010;3:1267-76.

8. Sengupta P. Health impacts of yoga and pranayama: a stateof-the-art review. Int J Prev Med 2012;3:444-58.

9. Brems C, Colgan D, Freeman H, Freitas J, Justice L, Shean M, et al. Elements of yogic practice: Perceptions of students in healthcare programs. Int J Yoga 2016;9:121-9.
10. Hunter SD, Dhindsa MS, Cunningham E, Tarumi T, Alkatan M, Nualnim N, et al. The effect of Bikram yoga on arterial stiffness in young and older adults. J Altern Complement Med 2013;19: 930-4.

11. Hunter SD, Dhindsa MS, Cunningham E, Tarumi T, Alkatan M, Nualnim N, et al. Impact of hot yoga on arterial stiffness and quality of life in normal and overweight/obese adults. J Phys Act Health 2016;13:1360-3.

12. Kumar PVG, Deshpande S, Joshi A, More P, Singh A, Nagendra HR. Effect of integrated yoga therapy on arterial stiffness: a pilot study on young and older adults with obesity. Integr Med Int 2017;4:85-93.

13. Patil SG, Aithala MR, Das KK. Effect of yoga on arterial stiffness in elderly subjects with increased pulse pressure: A randomized controlled study. Complement Ther Med 2015; 23:562-9.

14. Wooten SV, Gundersen SS, and Tanaka H. Hemodynamic and pressor responses to combination of yoga and blood flow restriction. Int J Sports Med 2020;41:759-65.

15. Kim S, Bemben MG, Bemben DA. Effects of an 8-month yoga intervention on arterial compliance and muscle strength in premenopausal women. J Sports Sci Med 2012;1:322-30.

16. Hunter SD, Tarumi T, Dhindsa MS, Nualnim N, Tanaka H. Hatha yoga and vascular function: results from cross-sectional and interventional studies. J Bodyw Mov Ther 2013;17:322-7.

17. Hunter SD, Laosiripisan J, Elmenshawy A. Effects of heated and thermoneutral yoga interventions on arterial stiffness in middle-aged adults. Complement Ther Med 2018;40:113-5.

18. Piña AA, Shadiow J, Tobi Fadeyi A, Chavez A, Hunter SD. The acute effects of vinyasa flow yoga on vascular function, lipid and glucose concentrations, and mood. Complement Ther Med 2021;56:102585.

19. Bhaskar L, Kharya C, Deepak KK and Kochupillai V. Assessment of Cardiac Autonomic Tone Following Long Sudarshan Kriya Yoga in Art of Living Practitioners. J Altern Complement Med 2017;23:705-12.

20. Trivedi GY, Patel V, Shah MH, Dhok MJ, Bhoyania K. Comparative study of the impact of active meditation protocol and silence meditation on heart rate variability and mood in women. Int $\mathrm{J}$ Yoga 2020;13:255-60.

21. Murugesan R, Govindarajulu N, Bera TK. Effect of selected yoga practices on the management of hypertension. Indian J Physiol Pharmacol 2000;44:207-10. 
22. Van der Zwan LP, Scheffer PG, Dekker JM, Stehouwer CD, Heine RJ, Teerlink T. Hyperglycemia and oxidative stress strengthen the association between myeloperoxidase and blood pressure. Hypertension 2010;55:1366-72.

23. Patil SG, Dhanakshirur GB, Aithala MR, Naregal G, Das KK. Effect of yoga on oxidative stress in elderly with grade-I hypertension: a randomized controlled study. JCDR 2014;8: BC04.

24. Incalza MA, D'Oria R, Natalicchio A, Perrini S, Laviola L, Giorgino F. Oxidative stress and reactive oxygen species in endothelial dysfunction associated with cardiovascular and metabolic diseases. Vascul Pharmacol 2018;100:1-19.

25. De Ciuceis C, Amiri F, Brassard P, Endemann DH, Touyz RM, Schiffrin EL. Reduced vascular remodeling, endothelial dysfunction, and oxidative stress in resistance arteries of angiotensin II-infused macrophage colony-stimulating factordeficient mice: evidence for a role in inflammation in angiotensin-induced vascular injury. Arterioscler Thromb Vasc Biol 2005;25:2106-13.

26. Li AW, Goldsmith CAW. The effects of yoga on anxiety and stress. Altern Med Rev 2012;17:21-35.

27. Azeez AM, Puri GD, Samra T, Singh M. Effect of short-term yoga-based-breathing on peri-operative anxiety in patients undergoing cardiac surgery. Int J Yoga 2021;14:163-7.

28. Parswani MJ, Sharma MP, lyengar SS. Mindfulness-based stress reduction program in coronary heart disease: $A$ randomized control trial. Int J Yoga 2013;6:111-7.

29. Streeter CC, Gerbarg PL, Saper RB, Ciraulo DA, Brown RP. Effects of yoga on the autonomic nervous system, gamma- aminobutyric-acid, and allostasis in epilepsy, depression, and post-traumatic stress disorder. Med Hypotheses 2012;78: 571-9.

30. Arora S, Bhattacharjee J. Modulation of immune responses in stress by Yoga. Int J Yoga 2008;1:45-55.

31. Esfahani HN, Zamani M, Marandi SM, Shaygannejad V, Javanmard $\mathrm{SH}$. Preventive effects of a three-month yoga intervention on endothelial function in patients with migraine. Int J Prev Med 2014;5:424-9.

32. Yang K. A review of yoga programs for four leading risk factors of chronic diseases. Evid Based Complement Alternat Med 2007;4:487-91.

33. Agyemang C, Addo J, Bhopal R, Aikins Ade G, Stronks K. Cardiovascular disease, diabetes and established risk factors among populations of sub-Saharan African descent in Europe: a literature review. Global Health 2009;5:7.

34. Manchanda SC. Yoga--a promising technique to control cardiovascular disease. Indian Heart J 2014;66:487-9.

35. Manchanda SC, Madan K. Yoga and meditation in cardiovascular disease. Clin Res Cardiol 2014;103:675-80.

36. Chu P, Gotink RA, Yeh GY, Goldie SJ, Hunink MG. The effectiveness of yoga in modifying risk factors for cardiovascular disease and metabolic syndrome: a systematic review and meta-analysis of randomized controlled trials. Eur J Prev Cardiol 2016;23:291-307.

37. Mooventhan A, Nivethitha L. Role of yoga in the prevention and management of various cardiovascular diseases and their risk factors: a comprehensive scientific evidence-based review. Explore (NY) 2020;16:257-63. 